Supplement of Atmos. Chem. Phys., 20, 1469-1481, 2020

https://doi.org/10.5194/acp-20-1469-2020-supplement

(C) Author(s) 2020. This work is distributed under

the Creative Commons Attribution 4.0 License.

(c) (1)

Supplement of

\title{
High secondary formation of nitrogen-containing organics (NOCs) and its possible link to oxidized organics and ammonium
}

\section{Guohua Zhang et al.}

Correspondence to: Xinhui Bi (bixh@gig.ac.cn)

The copyright of individual parts of the supplement might differ from the CC BY 4.0 License. 


\section{Instrumentation}

21 Individual particles are introduced into SPAMS through a critical orifice. They are

22 focused and accelerated to specific velocities, which are determined by two continuous

23 diode Nd:YAG laser beams (532 nm). Based on the measured velocities, a pulsed laser

24 (266 nm) downstream is trigger to desorp/ionize the particles. The produced positive and

25 negative molecular fragments are recorded. In summary, a velocity, a detection moment,

26 and an ion mass spectrum are recorded for each ionized particle, while there is no mass

27 spectrum for not ionized particles. The velocity could be converted to $d_{\mathrm{va}}$ based on a

28 calibration using polystyrene latex spheres (PSL, Duke Scientific Corp., Palo Alto) with

29 predefined sizes. It is noted that pure ammonium sulfate is difficult to be ionized under 266

$30 \mathrm{~nm}$ UV laser used in the SPAMS, although this may not be the case since we focused on

31 the NOCs-containing particles.

32 The concentrations of $\mathrm{NO}_{\mathrm{x}}$, and $\mathrm{O}_{3}$ were measured by Model $42 \mathrm{i}\left(\mathrm{NO}-\mathrm{NO}_{2}-\mathrm{NO}_{\mathrm{x}}\right)$

33 Analyzer, and Model 49i $\mathrm{O}_{3}$ Analyzer (Thermo Fisher Scientific Inc.), respectively. The

34 concentrations of $\mathrm{PM}_{2.5}$ were continuously measured using a tapered element oscillating

35 microbalance (TEOM 1405, Thermo Fisher Scientific Inc.), respectively.

\section{Positive matrix factorization}

38 PMF is a multivariate receptor model used to determine source factors, and it has

39 been used extensively with temporal variation data. In order to complement single

40 particle data analysis, we used USEPA PMF 5.0 (Norris et al., 2009) to group chemical

41 markers from all the detected particles. In such analysis, RPAs for ion markers were 
42 typically used as input in the PMF model. An uncertainty of 50\% in RPA was used due to

43 the shot-to-shot fluctuations of desorption laser and complex particle matrix (Zauscher et

44 al., 2013). Fourteen marker ions with were used, including sulfate $\left(\mathrm{m} / \mathrm{z}-97\left[\mathrm{HSO}_{4}\right]^{-}\right)$,

45 nitrate $\left(\mathrm{m} / \mathrm{z}-62\left[\mathrm{NO}_{3}\right]^{-}\right)$, ammonium $\left(\mathrm{m} / \mathrm{z} 18\left[\mathrm{NH}_{4}\right]^{+}\right)$, oxalate $\left(\mathrm{m} / \mathrm{z} 89\left[\mathrm{HC}_{2} \mathrm{O}_{4}\right]^{-}\right)$, oxidized

46 organics markers (at $m / z-45\left[\mathrm{HCO}_{2}\right]^{-}, \mathrm{m} / \mathrm{z}-59\left[\mathrm{CH}_{3} \mathrm{CO}_{2}\right]^{-}, \mathrm{m} / \mathrm{z}-71\left[\mathrm{C}_{3} \mathrm{H}_{3} \mathrm{O}_{2}\right]^{-}, \mathrm{m} / \mathrm{z}$ -

$4773\left[\mathrm{C}_{2} \mathrm{HO}_{3}\right]^{-}, \mathrm{m} / \mathrm{z}-87\left[\mathrm{C}_{3} \mathrm{H}_{3} \mathrm{O}_{3}\right]^{-}, \mathrm{m} / \mathrm{z}-103\left[\mathrm{C}_{3} \mathrm{H}_{3} \mathrm{O}_{4}\right]^{-}$, and $\left.\mathrm{m} / \mathrm{z}-117\left[\mathrm{C}_{4} \mathrm{H}_{5} \mathrm{O}_{4}\right]^{-}\right)$, organic

48 nitrogen markers (NOCs, sum of $m / z-42\left[\mathrm{CNO}^{-}\right.$and $-\mathrm{m} / \mathrm{z} 26[\mathrm{CN}]^{-}$), and other

49 carbonaceous fragments (i.e., $m / z 36\left[\mathrm{C}_{3}\right]^{+}, \mathrm{m} / \mathrm{z} 37\left[\mathrm{C}_{3} \mathrm{H}\right]^{+}$).

50 PMF solutions with $2-5$ factors were tested and showed convergence results. The

51 relevant Q values and $Q_{\text {robust }}$ / $Q_{\text {theory }}$ for these solutions are shown in Table S3. In these

52 solutions explored $\mathrm{Q}_{\text {robust }} / \mathrm{Q}_{\text {theory }}<1$, although it is recommended that $\mathrm{Q}_{\text {robust }} \approx \mathrm{Q}_{\text {theory }}$.

53 The 3-factor solution was chosen as the best because the measured versus predicted RPA

54 of more relevant chemical species (i.e., NOCs, the oxidized organics and ammonium) in

55 the PMF model had strong correlations $\left(\mathrm{R}^{2}=0.56-0.95\right)$, and also has the most

56 physically meaningful factors. The residuals of this solution were between -2 and 2 . In

57 the 4 and 5 -factor solution, with slightly stronger $\mathrm{R}^{2}$ values than the 3 -factor solution for

58 NOCs and ammonium, but had two similar oxalate factors or an additional methylglyoxal

59 factor, respectively, which seemed less physically meaningful. Bootstrapping on the 3-

60 factor solution shows stable results, with $>90$ out of 100 bootstrap factors mapped with

61 those in the based run. Fpeak value from -0.5 to 0.5 was examined, and an examination

62 of Q values showed the application of Fpeak of 0 giving the best result. 


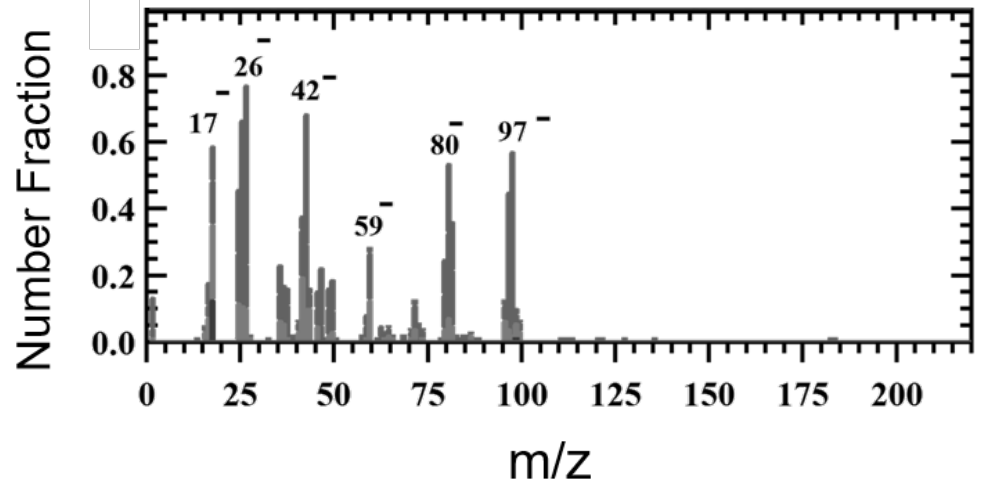

63

64

65 Figure S1. The number fraction of ion peaks versus $\mathrm{m} / \mathrm{z}$ from the bulk solution-phase

66 reaction of ammonium sulfate and methylglyoxal. The bulk solution-phase reaction was

67 prepared with $1 \mathrm{M}$ ammonium sulfate and $1 \mathrm{M}$ methylglyoxal solution, and aged in sealed

68 bottles under dark conditions and at room temperature for several days. BrC SOA formed

69 from such reaction has been previously reported to be significantly contributed from

70 NOCs (Sareen et al., 2010). 


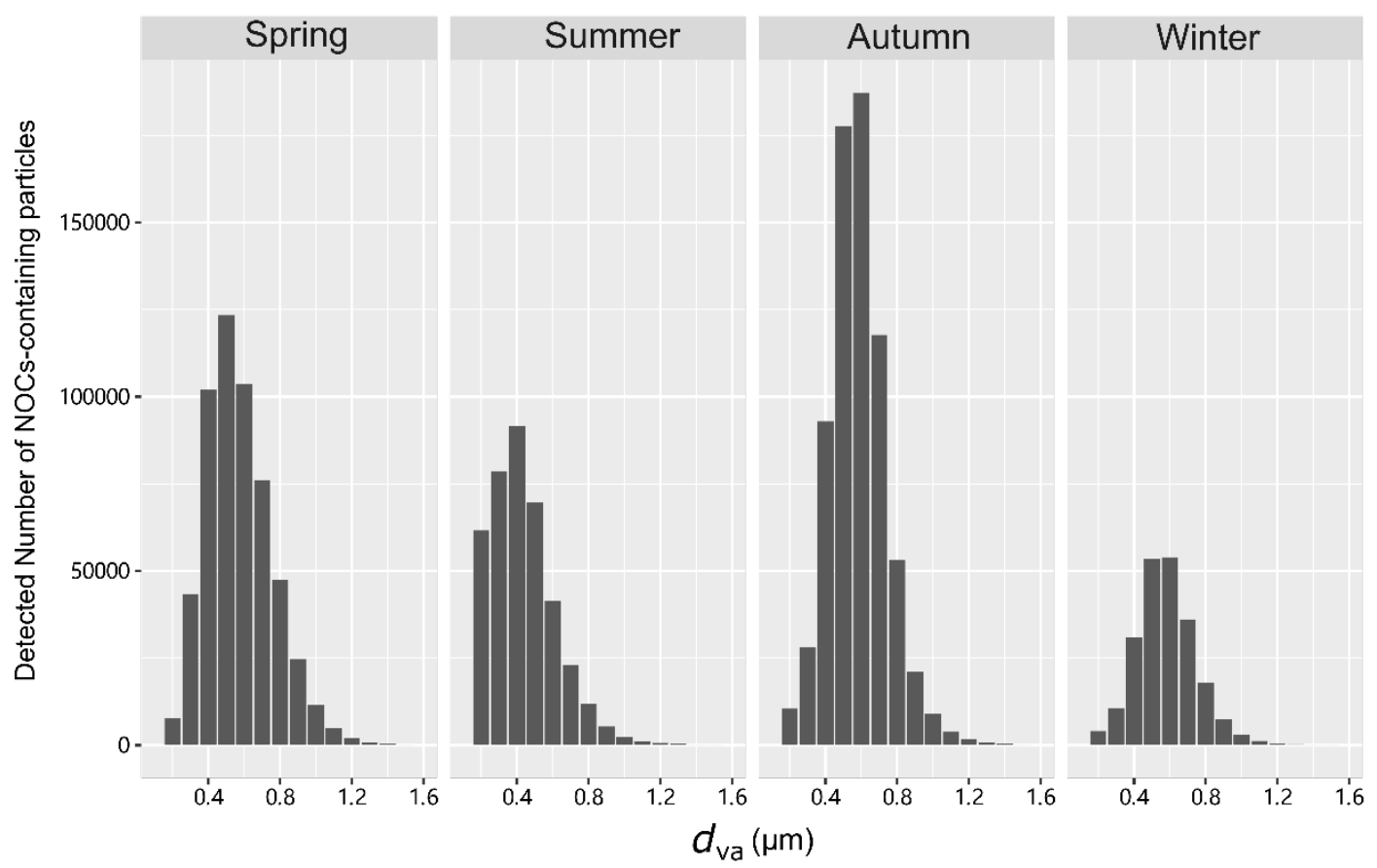

73 Figure S2. The detected number of NOC-containing particles as a function of $d_{\text {va. }}$. 


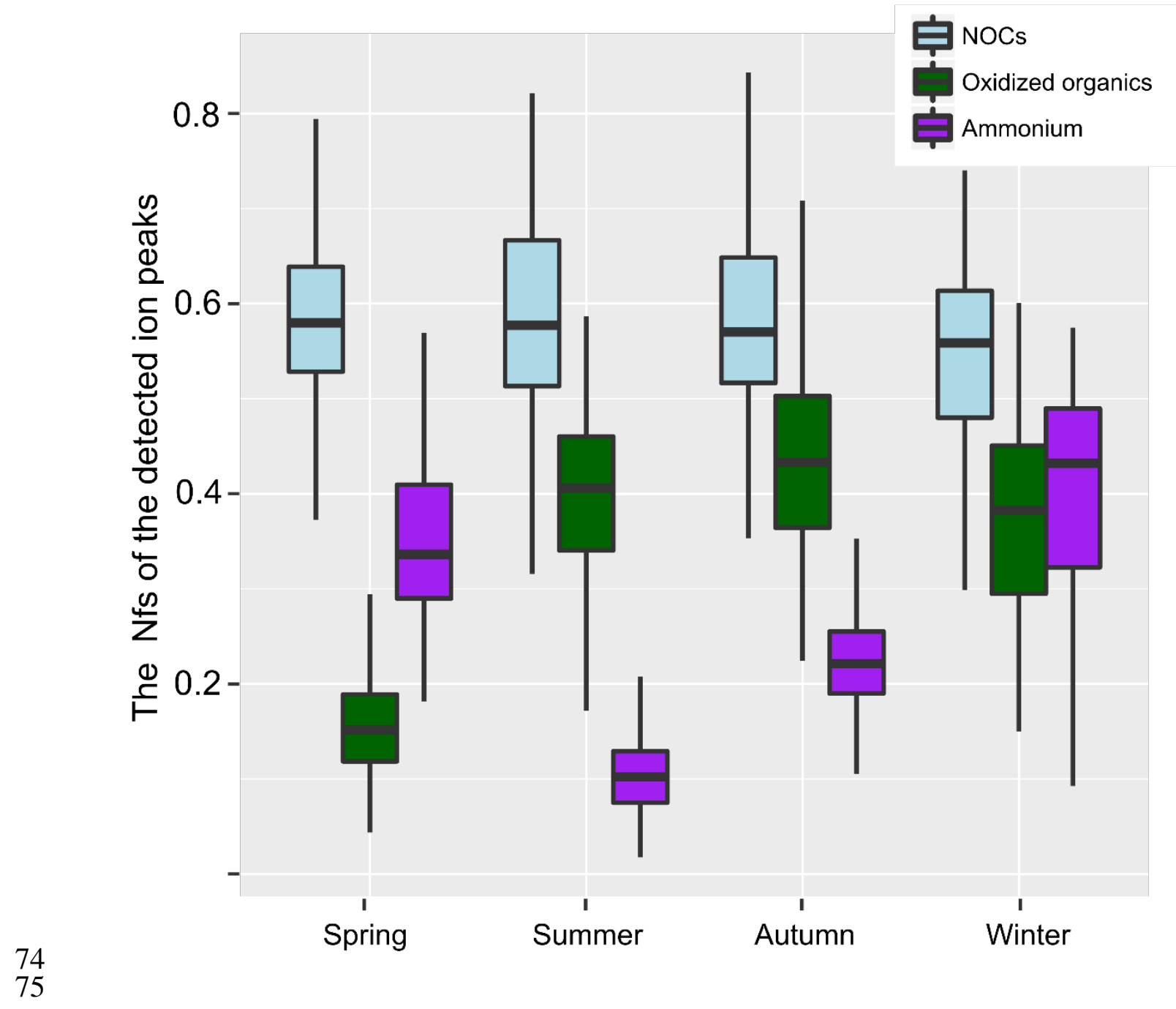

76 Figure S3. The distribution of the Nfs of the detected ion peaks over four seasons. 


\section{Limited dependence of NOCs on the oxidized organics during spring and}

\section{8 ammonium during summer}

79 During summer, the hourly detected number of NOCs showed a limited dependence 80 on ammonium (Fig. 3d). As shown in Fig. S4, the detected number of ammonium is

81 obviously lower than NOCs. In contrast, there were prevalent oxidized organics that were 82 associated with NOCs. Due to the volatility of ammonium nitrate, there is less particulate 83 ammonium in summer. Higher level of $\mathrm{NH}_{3}$ during summer (Pan et al., 2018) may have 84 potential influence on the formation of NOCs. Less dependence of NOCs on ammonium 85 could be due to the more predominant formation of secondary NOCs through the uptake 86 of $\mathrm{NH}_{3}$ and the following interactions with secondary oxidized organics. As shown by 87 Nguyen et al. (Nguyen et al., 2012), ammonia is more efficient for the formation of NOCs 88 in this pathway than ammonium. As also supported with PMF results shown in Fig. 5, the 89 oxidized organics factor dominant contributed to the predicted NOCs during warmer 90 seasons. Limited ammonium in this factor may also indicate that abundance of oxidized 91 organics during warmer season consumed the available ammonium. As discussed, such

92 chemistry would even lead to a reduction in the concentrations of $\mathrm{NH}_{3}$ and $\mathrm{NH}_{4}^{+}$through a 93 model simulation (Zhu et al., 2018). However, NOCs showed a limited dependent on the 94 oxidized organics during spring (Fig. 3a and 3b). Consistently, the lowest fraction of NOCs 95 that contained the oxidized organics was observed (Fig. S4), and ammonium factor 96 explained $\sim 80 \%$ of the predicted NOCs (Fig. 5) during spring. It is likely attributed to the

97 higher conversion of oxidized organics to the observed NOCs in humid air during spring 98 (Fig. 6 and Table S1). In addition, possible reasons might also include more primary NOCs 99 and unidentified oxidized organics. 
(a) Spring

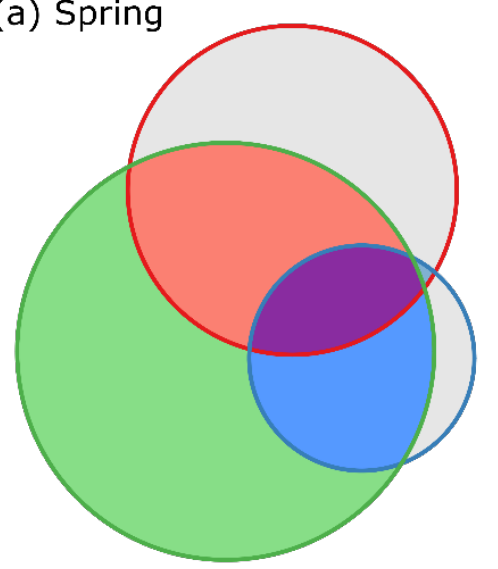

(b) Summer

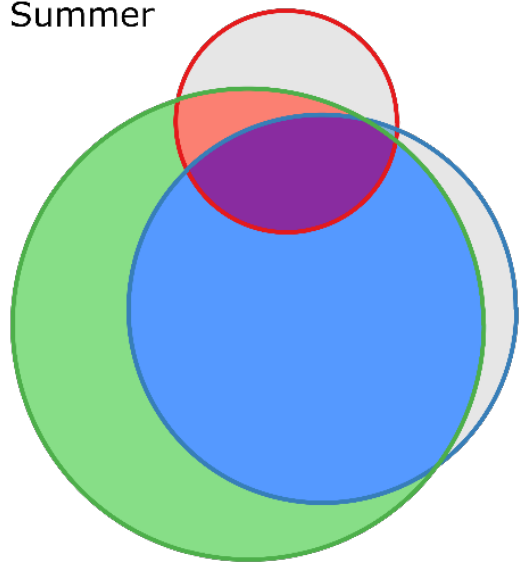

\section{Ammonium Oxidized organics NOCs}

(c) Autumn

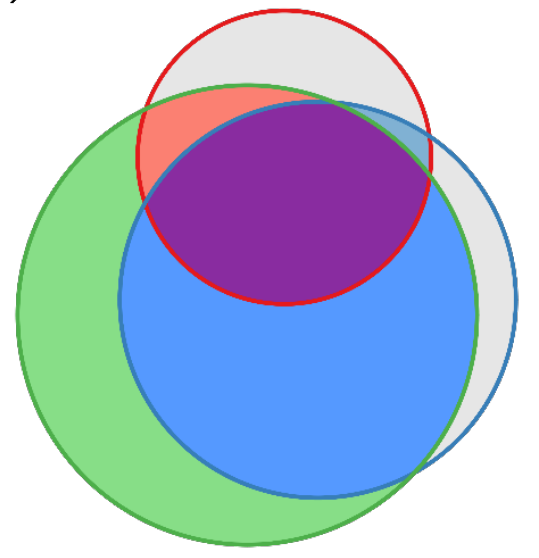

(d) Winter

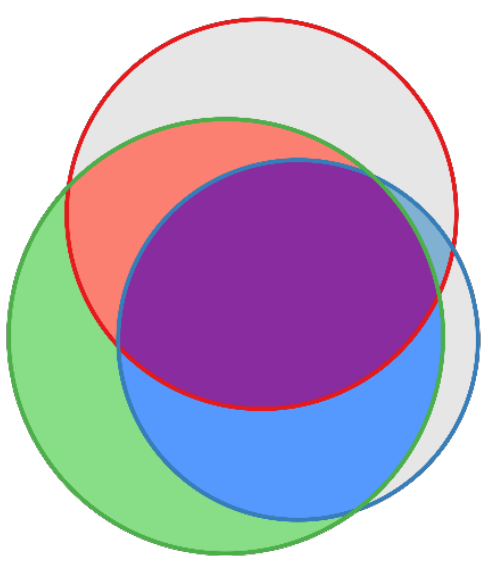

102 Figure S4. Venn plot of number based mixing state involving NOCs (green circle), the 103 oxidized organics (blue circle), and ammonium (red circle). 
104 Table S1. The number and Nfs of NOCs-containing particles in the all the detected

105 particles during four seasons, respectively. Standard errors for the Nfs of particles were

106 estimated assuming Poisson distribution (Pratt et al., 2010)(Pratt et al., 2010). Temperature

107 (T), relative humidity $(\mathrm{RH}), \mathrm{O}_{3}$, and $\mathrm{PM}_{2.5}$ were provided by Guangdong Environmental

108 Monitoring Center. The arriving air masses in Guangzhou, have been described previously:

109 prevalence of marine air masses in spring and summer, whereas northern air masses from

110 inland China in autumn and winter.

111

\begin{tabular}{lllll}
\hline & Spring & Summer & Autumn & Winter \\
\hline Num. of all the detected particles & 933934 & 719371 & 1202604 & 397637 \\
Nfs of NOCs-containing particles & $58.7 \pm 0.08 \%$ & $59.4 \pm 0.09 \%$ & $59.0 \pm 0.07 \%$ & $55.6 \pm 0.1 \%$ \\
Temperature $\left({ }^{\circ} \mathrm{C}\right)$ & $18.8 \pm 4.2$ & $29.0 \pm 2.7$ & $24.9 \pm 2.6$ & $11.3 \pm 2.3$ \\
Relative Humidity (\%) & $68.0 \pm 13.4$ & $66.0 \pm 11.4$ & $47.0 \pm 10.1$ & $43.0 \pm 19.1$ \\
$\mathrm{O}_{\mathrm{x}}\left(\mu \mathrm{g} \mathrm{m}^{-3}\right)$ & $100.4 \pm 43.7$ & $114.5 \pm 70.6$ & $136.3 \pm 35.4$ & $113.1 \pm 34.0$ \\
$\mathrm{PM}_{2.5}\left(\mu \mathrm{g} \mathrm{m}^{-3}\right)$ & $51.2 \pm 26.0$ & $31.9 \pm 21.0$ & $44.3 \pm 18.1$ & $55.3 \pm 28.9$ \\
\hline
\end{tabular}

112 
113 Table S2. Coefficients calculated with a multiple linear regression analysis of the

114 RPAs of NOCs and those of the oxidized organics and ammonium. All the regressions 115 show significant correlation, with the fitting coefficients shown with a standard error.

116

\begin{tabular}{lccc}
\hline & The oxidized organics & Ln (Ammonium) & $\mathrm{R}^{2}$ \\
\hline Spring & $4.24 \pm 0.36$ & $-0.0064 \pm 0.00057$ & 0.24 \\
Summer & $1.69 \pm 0.22$ & $-0.012 \pm 0.0013$ & 0.24 \\
Autumn & $1.27 \pm 0.09$ & $-0.0086 \pm 0.0011$ & 0.38 \\
Winter & $1.57 \pm 0.14$ & $-0.0010 \pm 0.00069$ & 0.57 \\
Autumn 2014 & $1.18 \pm 0.11$ & $-0.013 \pm 0.0042$ & 0.35 \\
\hline
\end{tabular}

$1 \overline{17}$ 
118 Table S3. Q values for PMF Analysis with different number of factors.

119

\begin{tabular}{clllllll}
\hline $\begin{array}{c}\text { Num. } \\
\text { of factors }\end{array}$ & $\begin{array}{l}\mathrm{R}^{2 \#} \text { for all the } \\
\text { input species }\end{array}$ & $\mathrm{R}^{2}$ for NOCs & $\mathrm{R}^{2}$ for the & $\mathrm{R}^{2}$ for ammonium & $\mathrm{Q}_{\text {robust }} *$ & $\mathrm{Q}_{\text {robust }} / \mathrm{Q}_{\text {theory }}$ \\
\hline 2 & $0.28-0.95$ & 0.28 & $0.44-0.95$ & 0.46 & & \\
\hline 3 & $0.25-0.95$ & 0.74 & $0.59-0.95$ & 0.56 & 8278 & 0.59 \\
4 & $0.49-0.92$ & 0.78 & $0.59-0.92$ & 0.64 & 6485 & 0.53 \\
5 & $0.41-0.94$ & 0.83 & $0.58-0.94$ & 0.66 & 4944 & 0.47 \\
\hline
\end{tabular}

120

$121 \quad{ }^{\#} \mathrm{R}^{2}$ between the observed and predicted species

$122 * \mathrm{Q}_{\text {robust }}$ with $\mathrm{F}_{\text {peak }}=0$. 

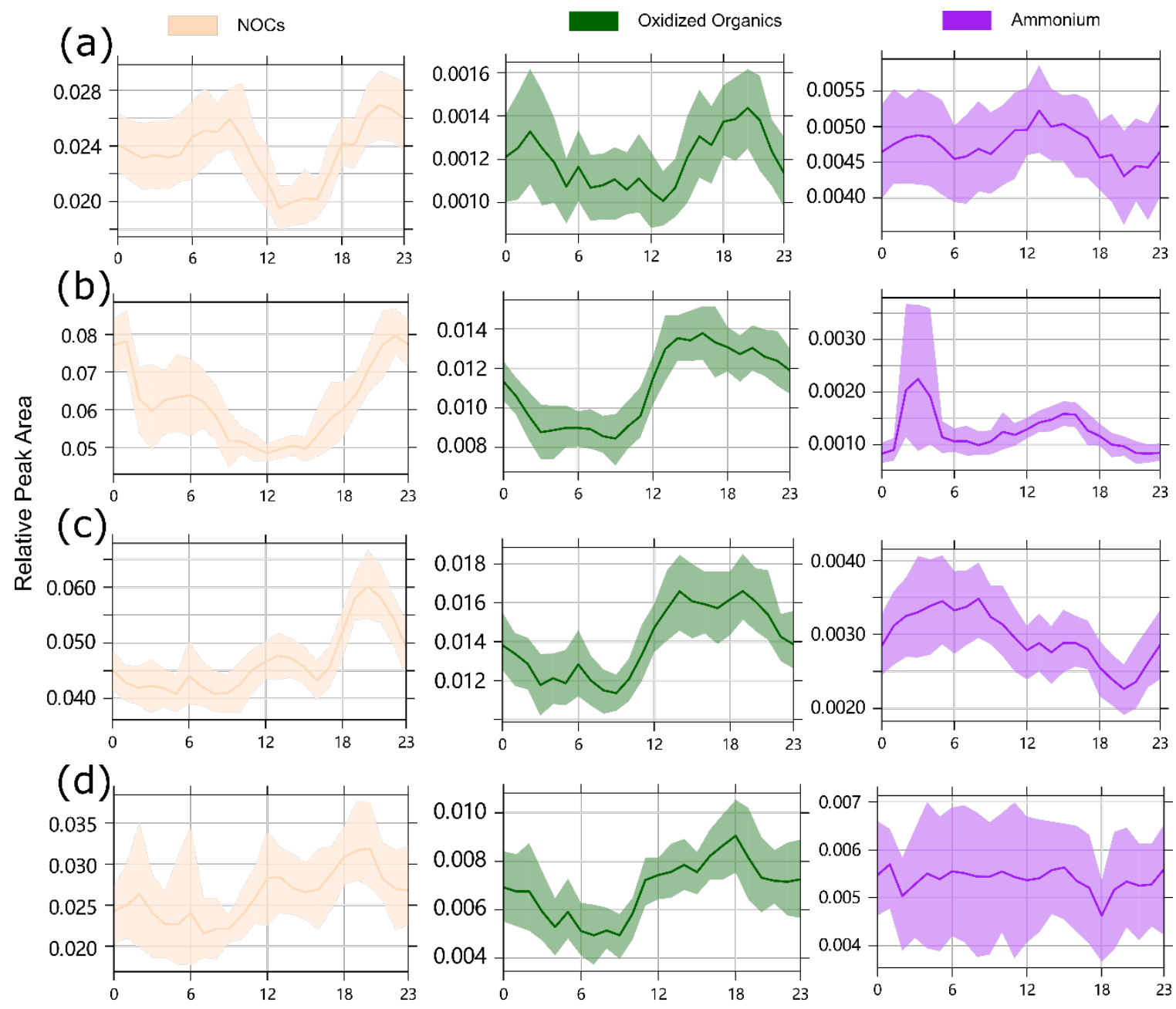

124

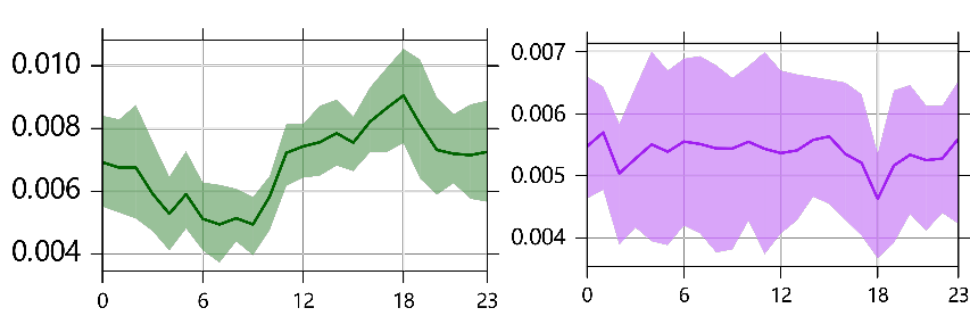

Hour of Day

125 Figure S5. Diurnal variations of RPAs of NOCs, oxidized organics, and ammonium from

126 spring to winter (a-d). 


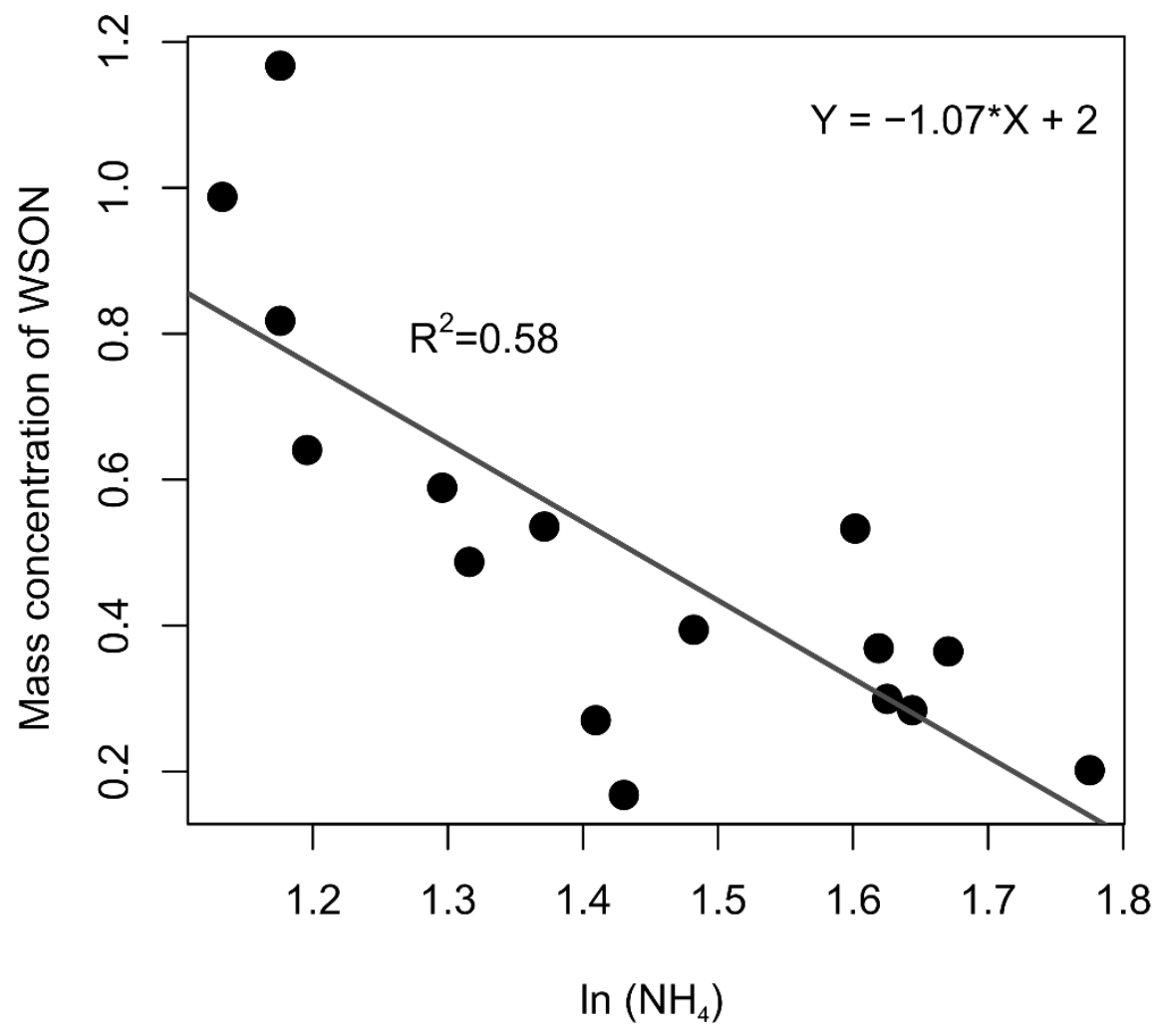

129 Figure S6. Relationship between the mass concentration of WSON and ammonium

130 (logarithmic transformed) in submicron particles during autumn of 2014. It is noted that

131 WSON (represented as the mass concentration of organic N) might not be properly

132 regarded as NOCs, as no significant correlation between daily mean mass

133 concentrations/fraction of WSON and the RPAs of NOCs. This is probably because the

134 daily mean values calculated for the RPAs of NOCs miss the temporal variation

135 information. Also, a part of NOCs might not be water-soluble (Cape et al., 2011).

136 During the autumn of 2014, daily size-resolved quartz fiber filter samples were

137 collected using an Andersen $\mathrm{PM}_{10}$ sampler equipped with a size-selective inlet high

138 volume cascade impactor (Model SA235, Andersen Instruments Inc.). The filters were

139 baked for $4 \mathrm{~h}$ in a muffle furnace at $500{ }^{\circ} \mathrm{C}$ before use. Water-soluble inorganic ions were 
140 analyzed by ion chromatography (Metrohm 883, Switzerland). In addition, water soluble

141 organic carbon (WSOC) and nitrogen (WSON) were analyzed by a Total Organic Carbon

142 Analysis Instrument (TOC, Germany). It is noted that NOCs, the oxidized organics, and

143 ammonium during this period also showed a similar relationship with that during autumn 144 of 2013. 

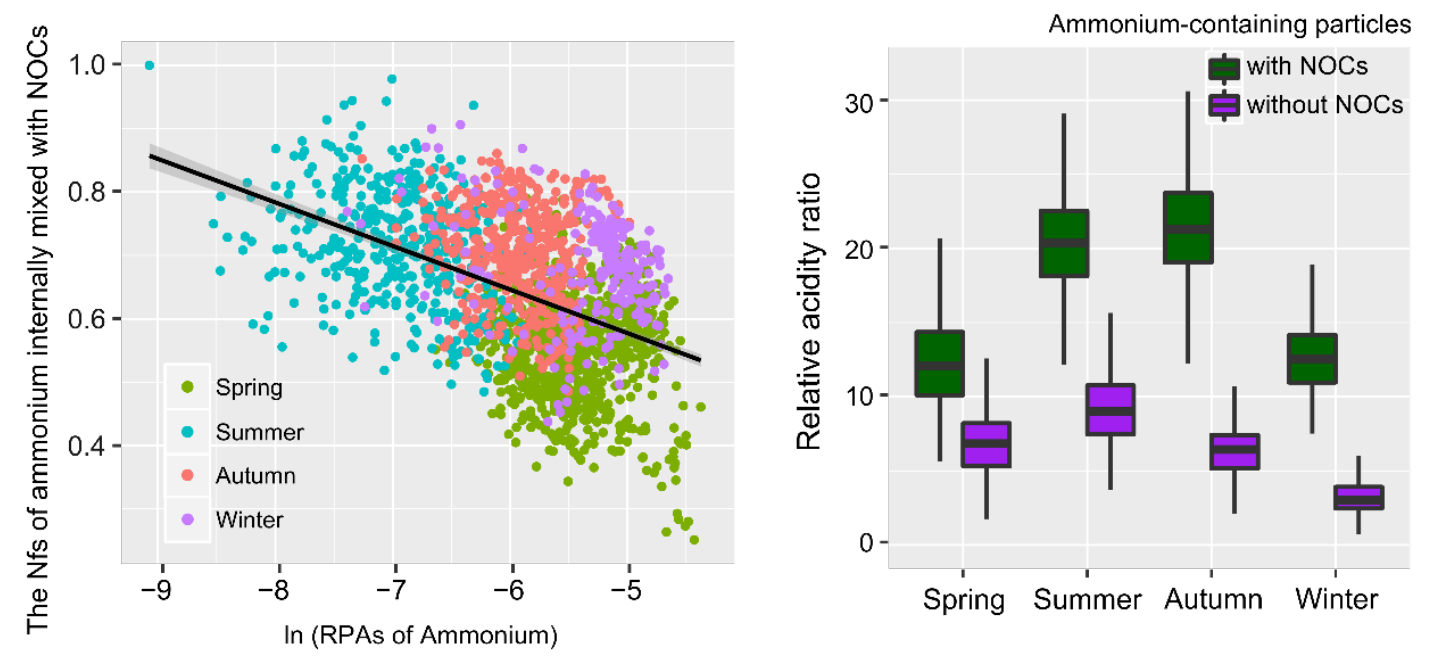

147 Figure S7. Relationship between the Nfs of ammonium that was internally mixed with

148 NOCs and RPAs of ammonium (left), and comparison of the relative acidity ratio

149 between ammonium-containing particles internally and externally mixed with NOCs

150 (right). 


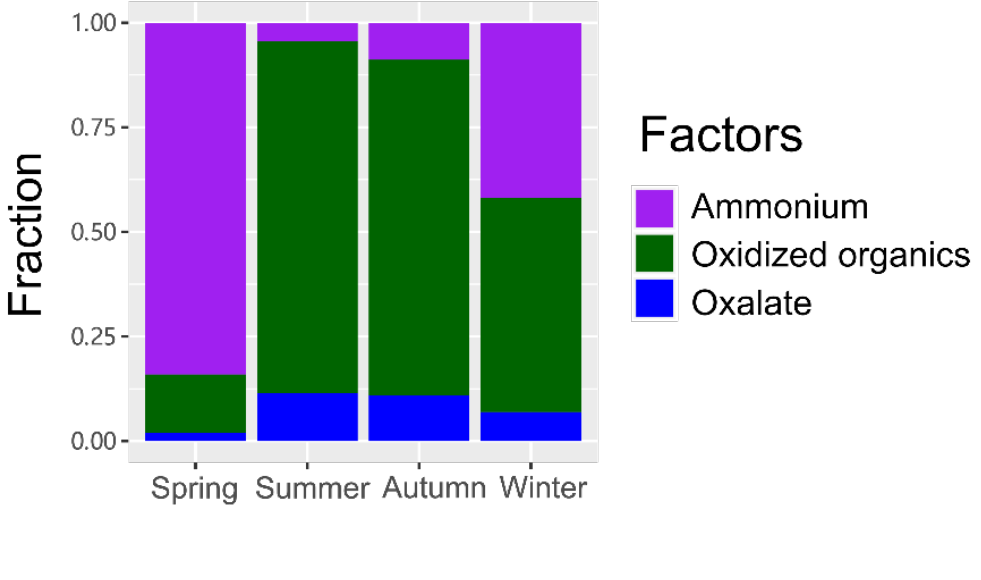

153 Figure S8. The relative contributions of the PMF-resolved 3-factor to the modelled NOCs 154 over the seasons. 
References

156 Cape, J. N., Cornell, S. E., Jickells, T. D., and Nemitz, E.: Organic nitrogen in the atmosphere - Where does it come from? A review of sources and methods, Atmos. Res., 102, 30-48, doi:10.1016/j.atmosres.2011.07.009, 2011.

Nguyen, T. B., Lee, P. B., Updyke, K. M., Bones, D. L., Laskin, J., Laskin, A., and Nizkorodov, S. A.: Formation of nitrogen- and sulfur-containing light-absorbing compounds accelerated by evaporation of water from secondary organic aerosols, J. Geophys. Res.-Atmos., 117, D01207, doi:10.1029/2011jd016944, 2012.

Norris, G., Vedantham, R., Wade, K., Zahn, P., Brown, S., Paatero, P., Eberly, S., and Foley, C. (2009), Guidance document for PMF applications with the Multilinear Engine, edited, Prepared for the U.S. Environmental Protection Agency, Research Triangle Park, NC.

Pan, Y. P., Tian, S. L., Zhao, Y. H., Zhang, L., Zhu, X. Y., Gao, J., Huang, W., Zhou, Y. B., Song, Y., Zhang, Q., and Wang, Y. S.: Identifying Ammonia Hotspots in China Using a National Observation Network, Environ. Sci. Technol., 52, 3926-3934, doi:10.1021/acs.est.7b05235, 2018.

Pratt, K. A., Heymsfield, A. J., Twohy, C. H., Murphy, S. M., DeMott, P. J., Hudson, J. G., Subramanian, R., Wang, Z. E., Seinfeld, J. H., and Prather, K. A.: In Situ Chemical Characterization of Aged Biomass-Burning Aerosols Impacting Cold Wave Clouds, J. Atmos. Sci., 67, 2451-2468, doi:10.1175/2010JAS3330.1, 2010.

Sareen, N., Schwier, A. N., Shapiro, E. L., Mitroo, D., and McNeill, V. F.: Secondary organic material formed by methylglyoxal in aqueous aerosol mimics, Atmos. Chem. Phys., 10, 997-1016, doi:10.5194/acp-10-997-2010, 2010.

Zauscher, M. D., Wang, Y., Moore, M. J. K., Gaston, C. J., and Prather, K. A.: Air Quality Impact and Physicochemical Aging of Biomass Burning Aerosols during the 2007 San Diego Wildfires, Environ. Sci. Technol., 47, 7633-7643, doi:10.1021/es4004137, 2013.

Zhu, S. P., Horne, J. R., Montoya-Aguilera, J., Hinks, M. L., Nizkorodov, S. A., and Dabdub, D.: Modeling reactive ammonia uptake by secondary organic aerosol in CMAQ: application to the continental US, Atmos. Chem. Phys., 18, 3641-3657, 
185 doi:10.5194/acp-18-3641-2018, 2018. 